\title{
Molecular Docking studies on a series of $C$ - dimethylated chalcones towards possible pharmacological agents
}

\author{
Rambabu Anandam', Vasu Babu \\ Ala $^{2}$, Bala Murali Krishna $\mathbf{K}^{\mathbf{1}}$, \\ Jyothi K Kasturi' ${ }^{1}$, Vijaya Durga \\ Trripuram $^{1}$, Parvathi Thota ${ }^{1}$, \\ Anitha Uppuluri ${ }^{1}$, Ravi Varala ${ }^{3}$, \\ Hari Babu Bollikolla ${ }^{1, *}$ \\ ${ }^{l}$ Department of Chemistry, Acharya \\ Nagarjuna University, Guntur-522 \\ 510, AP-India. \\ ${ }^{2}$ Department of Chemistry, QIS \\ College of Engineering and \\ Technology, Ongole, AP-India. \\ ${ }^{3}$ Scrips Pharma, Mallapur, \\ Hyderabad-500 076, Telangana, \\ India
}

\section{Corresponding Author}

\section{Hari Babu Bollikolla}

*Email: dr.b.haribabu@gmail.com

Article received: 06.05.2019

Article accepted: 29.08.2019

(C) 2019.The Authors. Published under Caribbean Journal of Science and Technology

ISSN 0799-3757

http://caribjscitech.com/

\begin{abstract}
:
An In Silico study was carried to know on a series of chalcone ligands to understand their binding pattern with various molecular targets and to evaluate the possible pharmacological potency with relevance to their literature reports. In order for this, molecular docking was carried out on the active molecules against IMPDH and PARP1 enzymes to find out their binding pattern. The analysis was done by testing ligands against various molecular targets like 1PAX, 4OQA, 3WIL, 1FCZ, 2ZBH, 1YQT, 1SRE and 1ME7 for various cancers, HIV, Immunotherapy, Viral infection, Inflammaation, etc.
\end{abstract}

Keywords: $C$-dimethyl chalcones; Ligands; In Silico, Molecular docking;

\section{Introduction}

A survey of literature revealed that many flavonoids benefit human health ${ }^{1}$. Alkylated flavonoids isolated from plants act as antimalarial ${ }^{2}$, antioxidant ${ }^{3}$, anticancer $^{4-6}$, anti-inflammatory ${ }^{7}$ and antimicrobial agents $^{8}$ like unsubstituted flavonoids. Anti-tubercular flavanones with methyl substitution on ring 'A' were isolated from Pisonia aculeate of Nyctaginaceae family and their analogs were also synthesized for possible anti-tubercular activity $^{10}$ along with their respective chalcones for inhibition on HIV integrase ${ }^{11}$.

The inflammation and fibrosis linked with TB could stimulate malignancy and triggered to blocking of lymphatics by pulmonary scarring and fibrosis initiating a delay in clearance of activated leucocytes. Subsequently, metastatic cell deposition was raised within fibrotic areas ${ }^{12}$. Instead, malnutrition and immunosuppression affected by cancer were described as likely primary causes of contraction or recurrence of TB infection. Wu et al ${ }^{13}$ have described cancer as one of the major risk factors for TB. The possibility of co-infection with TB was reported in patients with malignancy, especially those with lung cancer ${ }^{14}$. In the present conditions of drug resistance problem, dual acting agents against tuberculosis and cancer would be more beneficiary. In our continuous efforts for bioactive flavonoids here we made an attempt to develop the activity profile of the $C$-dimethylated chalcones (on ring 'A'). These synthesized compounds were screened for possible anti-cancer activity on A549 cell line (lung adenocarcinoma cell line) and anti-tuberculosis activity on the Mycobacterium tuberculosis strain. Further, molecular docking was also carried out on the active molecules against IMPDHand PARP1 enzymes to find out their binding pattern. 
Vasu Babu and co-workers, reported that the methyl substitution on ring 'A' of flavanone resulted in significant anti-tubercular activity against $H 37 R_{v}$ strain ${ }^{10}$ Further, there were various substituted chalcones which exhibits potent lipoxygenase inhibitory activity ${ }^{15}$ the effect few prenylated chalcones were investigated and multiple prenylated chalcones were found to become as lead compounds on 5-LOX inhibition ${ }^{16,17}$. Similarly, chalcones with methyl substitution on the aldehyde segment was observed to creates moderate inhibition on5-LOX and soyabeanlipoxygenase ${ }^{18,19}$. The literature on 5-LOX inhibition of chalcones and the 3D-QSAR studies endow with the essential pharmacophoric features of chalcones which is necessary for 5-LOX inhibition ${ }^{20}$. Five-LOX has been shown to play a major role in the pathogenesis of inflammatory diseases, which makes 5LOX inhibitors a highly attractive therapeutic option ${ }^{21}$.

Studies indicate that $\alpha, \beta$-unsaturated carbonyl based synthetic compounds inhibit phospholipase A2, lipoxygenases, neutrophil chemotaxis, phagocytosis, and the production of reactive oxygen species (ROS) ${ }^{22}$. However, the definite effects of chalcone derivatives in inflammatory mediators like 5-LOX were discussed ${ }^{23-25}$.

In 2015, a fresh series of $C$-alkylated chalcones with methyl, di-methyl ethyl and n-propyl groups on ring 'B' were designed and synthesized ${ }^{26}$ by available conventional approaches. Further, the molecules were attempted for the potency of 5-LOX inhibitory activity ${ }^{26}$ and got good results. Among the series, it was observed that substitutions such as methoxy/ethoxy at para-position and ortho- position on chalcone moiety might be significant factors for 5-LOX inhibition activity. The study of binding modes by molecular docking simulations was suggested that probably these ligands may act by interacting with the predictive allosteric active site of the soybean lipoxygenase (PDB: 1RRH) instead of metal binding site.

\section{Experimental}

\section{Materials and Methods}

Hardware and software: All the In Silico molecular docking studies reported herein were performed on Lenovo Ultra Book Laptop with Intel ${ }^{\circledR}$ Core $^{\mathrm{TM}}$ i5-3317U CPU @ $1.70 \mathrm{GHz}, \mathrm{RAM} 4 \mathrm{~GB}$ of operating system Windows 7 Home Basic. Schrödinger Small-Molecule Drug Discovery Suite Release 2013-127 and the products included therein were utilized for carryout different various molecular docking operations.

\section{Docking study}

This docking study aims to propose possible active molecular targets for the selected in-house molecules (Fig. 1). Target Structures-Glide version 5. $\mathbf{7}^{28-30}$, as implemented in Schrödinger suite 2013-1, was utilized for doing docking studies of the ligands 9a to 9q. Fig. 1 lists the selected ligand molecules used for docking studies in the ligand-binding sites against the targets listed in Table 2.

\section{Strategies were used for docking purpose:}

a) PharmMapper ${ }^{31}$ search

b) Protein Data Bank (PDB) ${ }^{32}$ search.

PharmMapper Server is an up-to-date integrated pharmacophore matching platform in particular appropriate for small or simple molecules to identify the potential molecular target. The input for such investigation is the small molecule structure (.mol2 format). The results encompass hit-list of userdefined number potential macromolecular targets (default is 300) with number of pharmacophore features matched, fitness scores and related scores.

The details of the statistics can be found elsewhere ${ }^{31}$ and for PharmMapper search, the molecular structure of ligand 9a (Fig. 1) was used as the representative for all the screening molecules. 

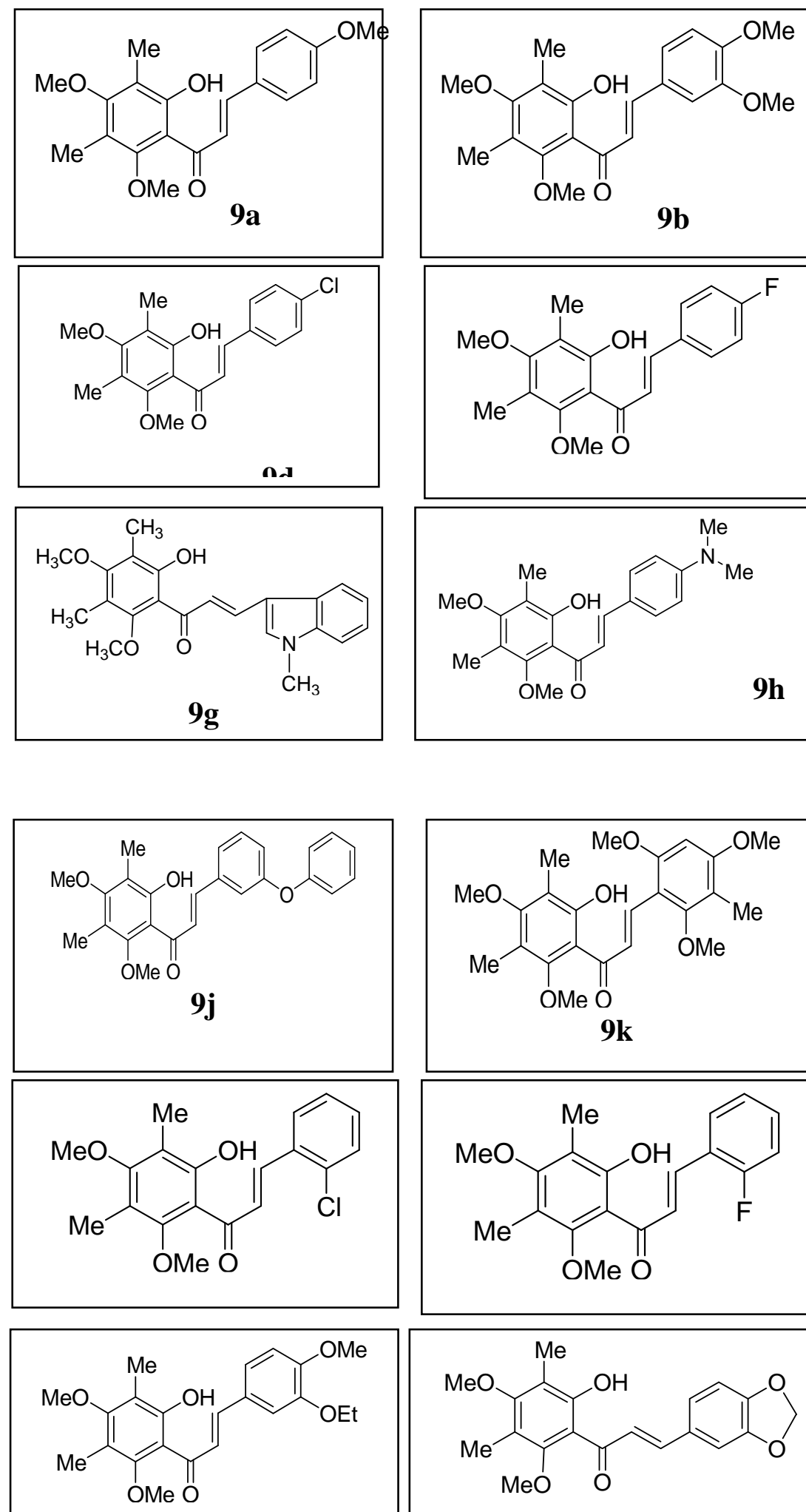

9p

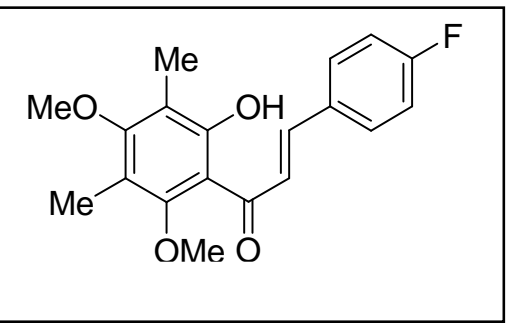

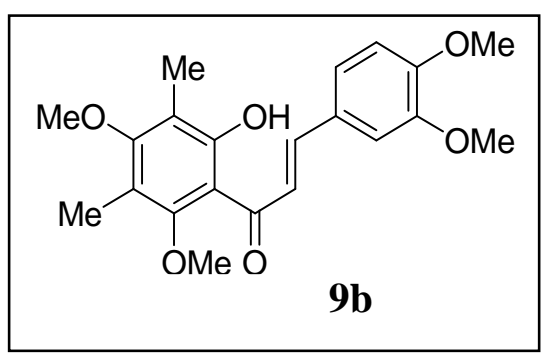
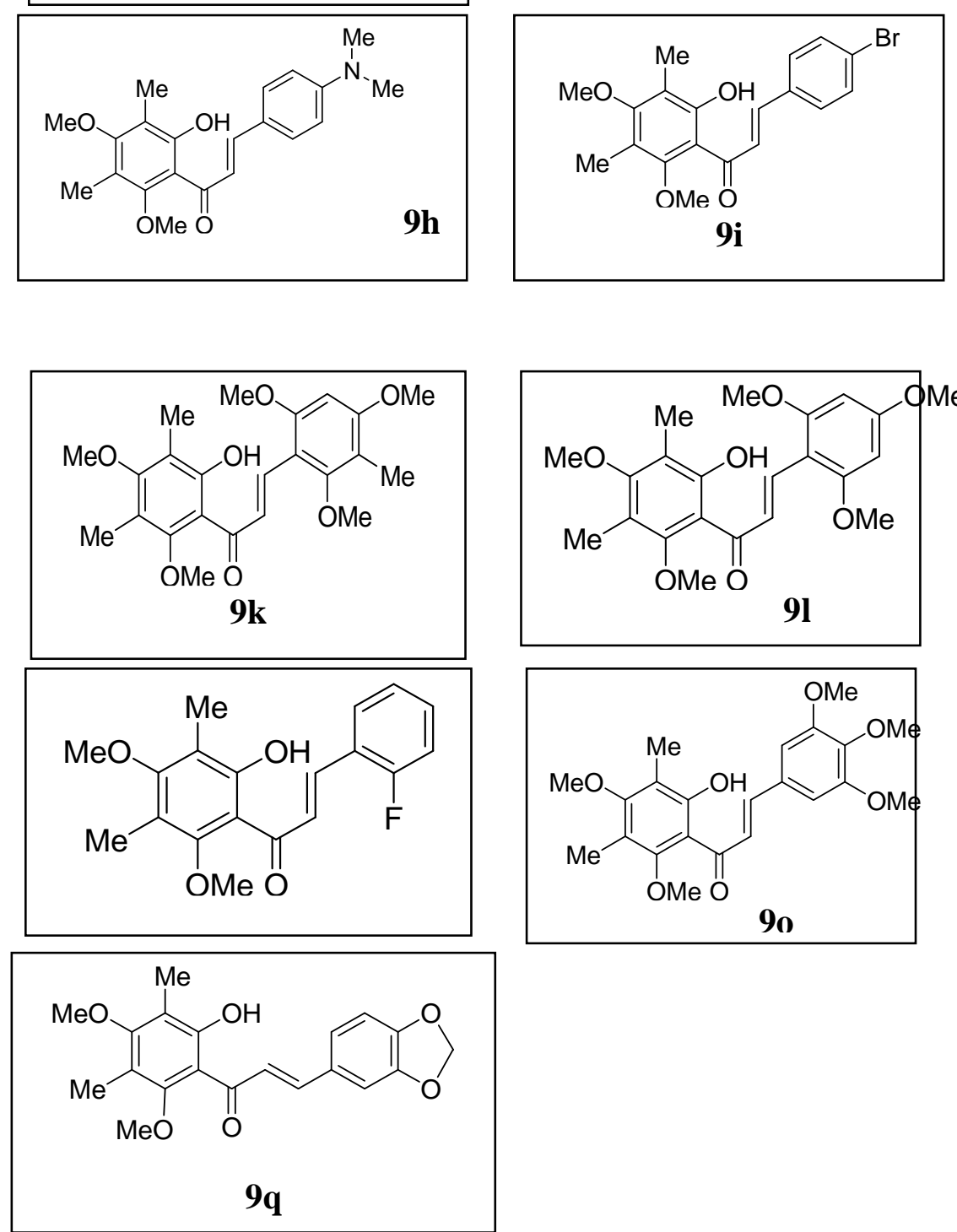
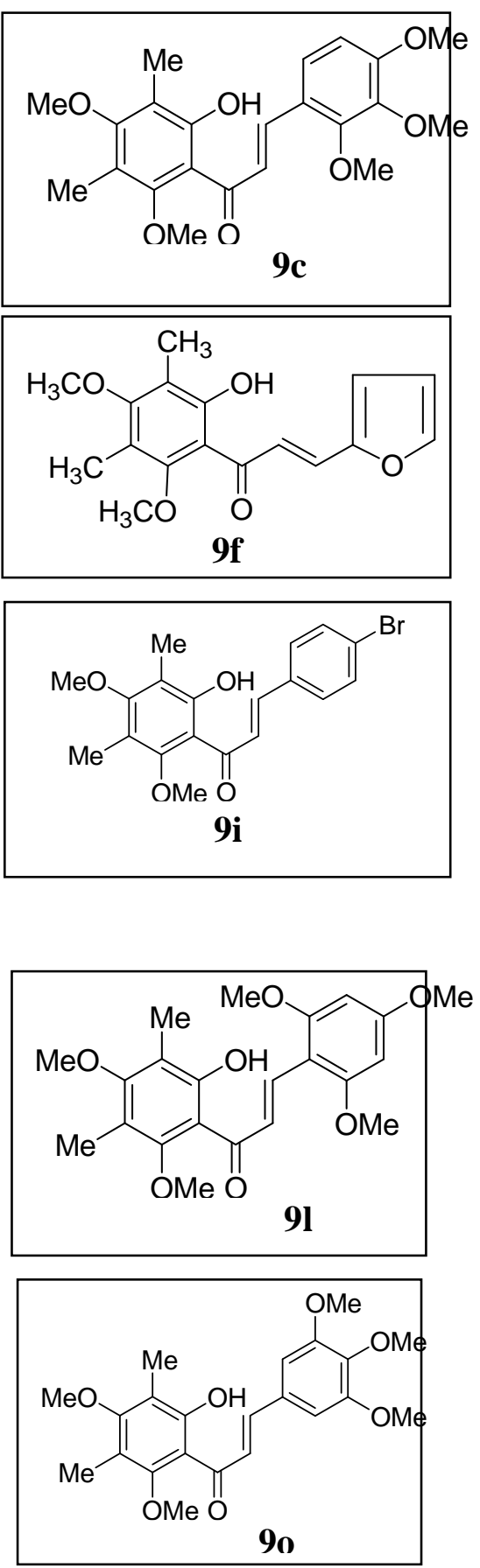

\footnotetext{
Fig. 1: Molecular Structures of the ligands 9a through 9q
} 
Advanced options for Conformation Generation (Energy Minimization: Yes) and Pharmacophore Mapping (Perform GA Match: Yes) were adopted with rest of the default values before submitting the job and the hit list (top 100 targets) was inspected manually. The top 10 targets were then used for docking ligands $9 \mathbf{9}$ to $\mathbf{9 q}$ to further validate the PharmMapper results. Fig. 2 shows the pharmacophoric features matched for one of the hits (Poly [ADP-ribose] polymerase 1, PARP, PDB ID 1PAX).
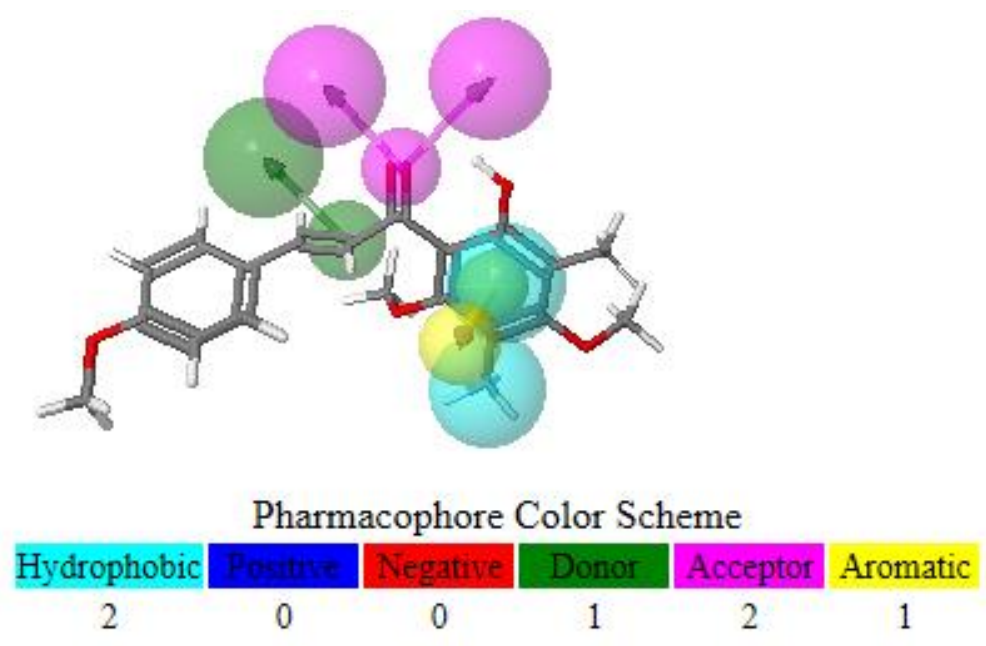

Fig. 2: Pharmacophore features derived from PARP-1 structure (PDB ID: 1PAX) mapped onto the molecular structure of ligand 9 a.

For PDB ligand search, minimum common substructure (MCS) of the in-house molecules (Fig. 1), i.e., chalcone $(\mathrm{PhC}(=\mathrm{O}) \mathrm{C}=\mathrm{CPh})$, was used. The assumption was that any PDB ligand matching with the chalcone MCS is likely to be the target of the in-house molecules due to structural similarity with the ligand. A total of nine PDB structures containing the chalcone MCS were found (data not shown). All the PDB structures with ligands were inspected manually. Some of these structures were then used for the docking studies. The results are summarized in Table 2.

\section{Receptor Grid Generation:}

The crystal structures listed in Table 2 were imported in Maestro $9.4^{27}$ and were subjected to Protein Preparation. All the default settings taken were used as implemented. The terminis were capped, and missing side chains were added using Prime version 3.2. All the water molecules were removed. H-bonds were optimized and, in the end, restrained minimization was studied wherein the heavy atoms were converged to root mean square deviation (RMSD) $0.3 \AA$. By using default settings, the prepared protein was then subjected to further minimization using Prime 3.2. after that the final refined protein structure was used for Receptor Grid Generation (Glide 5.9). The native ligand present in the target structure was used for placing the enclosing box. The grid was then used for docking the selected ligands in the ligand-binding site.

\section{Small Molecule Ligands Preparation:}

The ligand structures of Fig. 1 were built in Maestro. All the molecular structures were then subjected to Lig. Prep2.6, as implemented in Schrödinger suite 2013-1 and all the default settings were made as is. Finally, the set of molecular ligands were then subjected to docking studies.

\section{Results and Discussion}

The designed ligands (9a-q; provided in Fig. 1) were evaluated for possible therapeutic Area(s) by using In Silico models. To this purpose of docking studies, Extra Precision (XP) mode was taken. The docked poses were 
minimized and RMSD to input ligand geometries were determined. The docking scores for all the in-house molecules or ligands (9a-q) and the macromolecular targets are shown in Table 2. Figures 3-10 show the docking poses of representative molecules into the ligand-binding sites of each of the targets listed in Table 2. After docking studies, the pose viewer file was then used as input for Prime-MMGBSA calculations. The MMGBSA binding energies of the top-ranked pose for each molecule for each of the targets are summarized in Table 3 . The details of the targets used along with PDB ID of source for use as therapeutic purposes were provided with suitable references in Table 4.

Table 2: Results of docking analyses of in-house molecules (9a to 9q)

\begin{tabular}{|c|c|c|c|c|c|c|c|c|c|}
\hline \multirow{2}{*}{ S. No } & \multirow{2}{*}{ Compd. } & \multicolumn{8}{|c|}{ XP Docking Score } \\
\hline & & 1PAX $^{*}$ & 4OQA & 3WIL $^{\#}$ & $1 F C Z^{\#}$ & 2ZBH $^{\#}$ & 1YQT* & 1SRE* & 1ME7* \\
\hline 1 & 9a & -8.890 & -7.335 & -7.703 & -8.641 & -3.615 & -5.247 & -5.116 & -6.933 \\
\hline 2 & $9 \mathrm{~b}$ & -7.823 & -7.288 & -7.308 & -8.373 & -4.375 & -4.171 & -7.430 & -9.574 \\
\hline 3 & $9 \mathrm{c}$ & -8.877 & -7.075 & -7.329 & -6.271 & -2.779 & -4.876 & -6.466 & -6.414 \\
\hline 4 & 9d & -8.818 & -7.280 & -8.144 & -7.787 & -4.413 & -4.136 & -7.585 & -6.536 \\
\hline 5 & $9 e$ & -8.539 & -7.676 & -7.762 & -7.803 & -4.327 & -5.062 & -5.225 & -6.650 \\
\hline 6 & 9f & -8.088 & -7.459 & -7.420 & -8.053 & -3.399 & -4.578 & -6.231 & -8.818 \\
\hline 7 & 9g & -8.171 & -8.600 & -8.339 & - & -4.871 & -4.387 & -4.984 & -6.380 \\
\hline 8 & $9 \mathrm{~h}$ & -7.737 & -6.987 & -7.042 & -10.206 & -3.338 & -4.249 & -8.279 & -5.921 \\
\hline 9 & $9 \mathbf{i}$ & -8.779 & -7.954 & -8.088 & -9.261 & -4.190 & -5.182 & -7.481 & -5.588 \\
\hline 10 & 9j & -6.841 & -7.905 & -7.328 & - & -4.114 & -4.846 & -8.667 & -7.657 \\
\hline 11 & $9 k$ & -9.318 & -8.519 & -7.243 & - & -1.443 & -7.878 & -8.090 & -7.084 \\
\hline 12 & 91 & -9.021 & -8.285 & -7.133 & - & -2.720 & -4.684 & -5.575 & -7.764 \\
\hline 13 & $9 \mathrm{~m}$ & -8.786 & -7.878 & -9.004 & - & -4.124 & -3.883 & -5.303 & -7.078 \\
\hline 14 & $9 n$ & -8.579 & -7.263 & -8.673 & -8.305 & -4.243 & -3.659 & -7.368 & -6.716 \\
\hline 15 & 90 & - & - & - & - & - & - & - & - \\
\hline 16 & $9 p$ & -8.634 & -7.845 & -8.462 & -5.970 & -3.393 & -5.141 & -6.732 & -7.815 \\
\hline 17 & $9 q$ & -8.968 & -8.090 & -8.003 & -8.810 & -3.911 & -4.751 & -4.751 & -7.848 \\
\hline 18 & $\begin{array}{l}\text { Native } \\
\text { ligand }\end{array}$ & -9.474 & -9.869 & $\begin{array}{c}- \\
11.029\end{array}$ & -17.883 & -4.636 & -17.413 & -4.758 & -5.681 \\
\hline
\end{tabular}

* PharmMapperSearch; ${ }^{\# P D B}$ Ligand Search

Table 3: MMGBSA binding energies of in-house molecules (9a through 9q)

\begin{tabular}{|c|c|c|c|c|c|c|c|c|c|}
\hline \multirow{2}{*}{ S. No. } & \multirow{2}{*}{ Compd. } & \multicolumn{8}{|c|}{ MMGBSA Binding Energy (kcal/mol) } \\
\hline & & 1PAX $^{*}$ & 4OQA $^{\#}$ & 3WIL ${ }^{\#}$ & $1 \mathbf{F C Z}{ }^{\#}$ & $\mathbf{2 Z B H}^{\#}$ & 1YQT* & 1SRE* & 1ME7* \\
\hline 1 & 9a & -73.72 & -74.05 & -76.81 & -97.85 & -61.63 & -56.56 & \multirow{11}{*}{ N.C. } & -72.60 \\
\hline 2 & 9b & -78.10 & -69.60 & -86.64 & -91.87 & -63.13 & -55.81 & & -78.16 \\
\hline 3 & 9c & -82.08 & -78.17 & -81.53 & -46.16 & -50.20 & -44.79 & & -80.25 \\
\hline 4 & 9d & -77.72 & -77.22 & -82.11 & -107.82 & -63.30 & -43.77 & & -71.38 \\
\hline 5 & 9e & -71.17 & -60.50 & -78.89 & -97.69 & -55.26 & -47.87 & & -65.66 \\
\hline 6 & 9f & -71.99 & -76.21 & -71.63 & -92.74 & -56.58 & -47.34 & & -55.23 \\
\hline 7 & $9 \mathrm{~g}$ & -75.98 & -73.03 & -74.58 & - & -54.26 & -47.35 & & -70.12 \\
\hline 8 & $9 \mathrm{~h}$ & -75.22 & -65.18 & -75.58 & -91.31 & -67.07 & -36.81 & & -73.44 \\
\hline 9 & $9 \mathbf{i}$ & -77.17 & -69.32 & -82.41 & -114.98 & -61.98 & -51.69 & & -71.15 \\
\hline 10 & $9 j$ & -72.94 & -73.33 & -70.28 & - & -62.16 & -53.38 & & -81.05 \\
\hline 11 & 9k & -82.77 & -84.03 & -77.17 & - & -46.46 & -48.32 & & -57.68 \\
\hline
\end{tabular}




\begin{tabular}{|c|c|c|c|c|c|c|c|c|}
\hline 12 & 91 & -79.08 & -86.15 & -70.28 & - & -55.36 & -59.89 & \\
\hline 13 & $\mathbf{9 m}$ & -85.22 & -78.11 & -90.85 & - & -60.44 & -48.29 \\
\hline 14 & $\mathbf{9 n}$ & -74.24 & -72.93 & -76.89 & -91.33 & -57.08 & -29.72 \\
\hline 15 & $\mathbf{9 0}$ & - & - & - & - & - & - \\
\hline 16 & $\mathbf{9 p}$ & -83.60 & -80.98 & -91.29 & -61.40 & -67.52 & -52.73 \\
\hline 17 & $\mathbf{9 q}$ & -71.42 & -67.52 & -74.03 & -92.38 & -58.79 & -63.75 \\
\hline 18 & $\begin{array}{l}\text { Native } \\
\text { ligand }\end{array}$ & -62.41 & -85.88 & -91.65 & -163.62 & -72.68 & -67.43 & -66.33 \\
\hline & & & & & & -68.59 \\
\hline
\end{tabular}

* PharmMapperSearch; ${ }^{\#}$

PDB Ligand Search; N.C. Not calculated

From Tables 2 and 3, the ligand 9k showed the highest docking score of -9.318 with a binding energy of $82.77 \mathrm{kcal} / \mathrm{mol}$ on 1PAX (PharmMapper) molecular target compared to all other ligands which indicate the more ligand-molecular target interaction leading for possible cancer therapeutic area (Table 4) for ligand 9k.

Table 4: Details of Potential Macromolecular Targets of the In-house Molecules

\begin{tabular}{|c|c|c|c|c|}
\hline S. No. & Target & $\begin{array}{ll}\text { PDB } & \text { ID } \\
\text { (Source) } & \end{array}$ & Therapeutic Area(s) & Reference \\
\hline 1 & $\begin{array}{ll}\begin{array}{l}\text { Poly(ADP-ribose) } \\
\text { (PARP) }\end{array} & \text { polymerase } \\
\end{array}$ & $\begin{array}{l}\text { PAX } \\
\text { (Chicken) }\end{array}$ & Cancer & 33 \\
\hline 2 & $\begin{array}{l}\text { Poly(ADP-ribose) polymerase } 1 \\
\text { (PARP-1) }\end{array}$ & $\begin{array}{l}\text { 4OQA } \\
\text { (Human) }\end{array}$ & Cancer & 34 \\
\hline 3 & Serine/Threonine kinsase CK2 & $\begin{array}{l}\text { 3WIL } \\
\text { (Human) }\end{array}$ & Cancer & 35 \\
\hline 4 & $\begin{array}{l}\text { Human retinoic acid receptor } \\
\text { (hRAR) }\end{array}$ & 1FCZ (Human) & $\begin{array}{l}\text { Breast cancer and acute } \\
\text { promyelocytic leukemia }\end{array}$ & 36 \\
\hline 5 & Phospholipase A2 & 2ZBH (Snake) & $\begin{array}{l}\text { Neurodegenerative } \\
\text { psychiatric disorders }\end{array}$ & 37 \\
\hline 6 & RNase-L inhibitor (RLI) & 1YQT (Yeast) & HIV infection & 38 \\
\hline 7 & Streptavidin & $\begin{array}{l}\text { 1SRE } \\
\text { (Bacteria) }\end{array}$ & Immunotherapy & 39 \\
\hline 8 & $\begin{array}{l}\text { Inosine } 5 \text { '-monophosphate } \\
\text { dehydrogenase }\end{array}$ & $\begin{array}{l}\text { 1ME7 } \\
\text { (Protozoa) }\end{array}$ & $\begin{array}{l}\text { Cancer, Viral infections, } \\
\text { Inflammation, } \\
\text { Immunosuppression, Parasitic } \\
\text { infestations }\end{array}$ & 40 \\
\hline
\end{tabular}

Further, Figure 3a shows the binding mode of compound $\mathbf{9 k}$ in the active site of PARP enzyme (PDB ID: 1PAX) in this the native ligand is shown as green ball-and-stick model and compound $9 \mathbf{k}$ is shown in cyan ball-andstick model with H-bonds as black dotted line with the enzyme residues. Figure 3bshows the 2D depiction of the binding mode of compound 9k with H-bonds and pi-pi stacking interactions of the ligand with the macromolecule. Moreover, the compound $9 \mathbf{k}$ was also found to be active against molecular target 1YQT, which is representative for HIV therapeutic use. The docking score was found to be -7.878 and the binding energy was found to be-

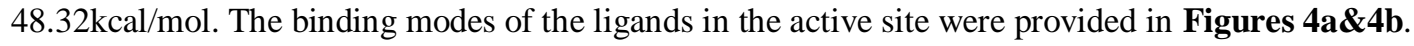




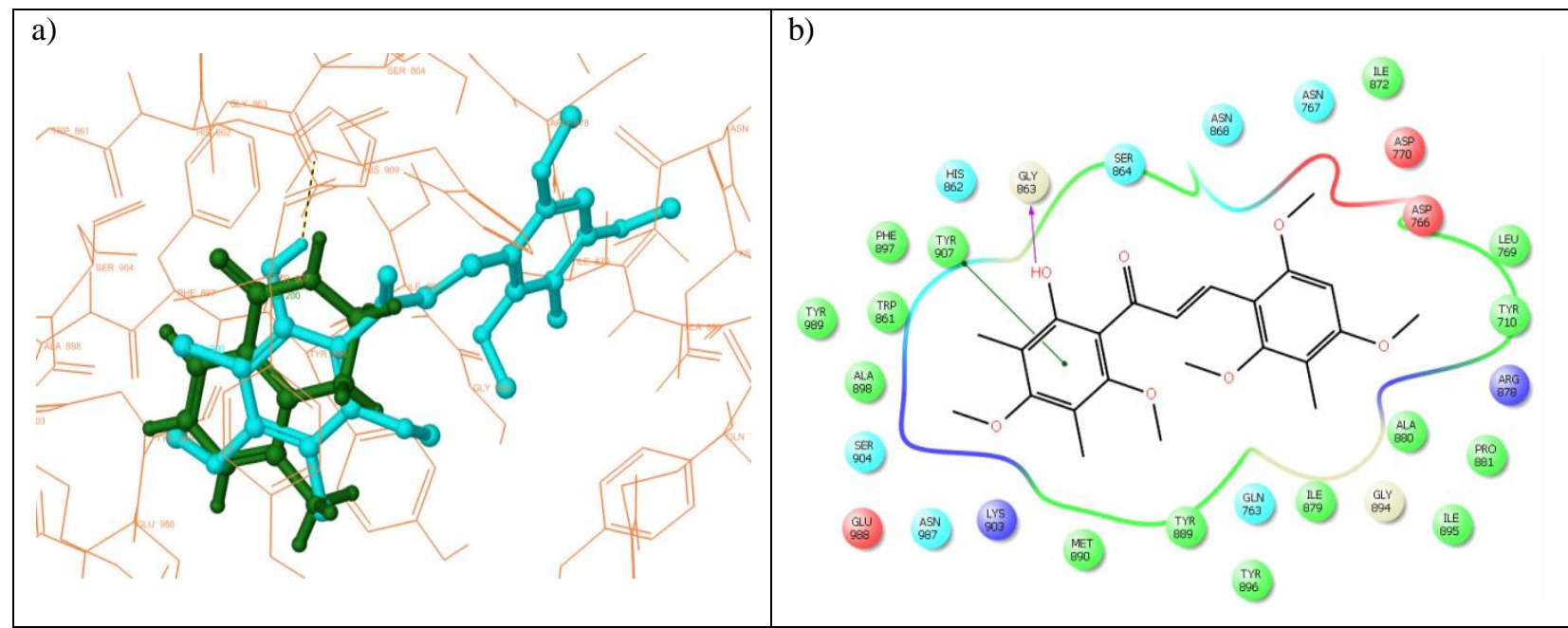

Fig. 3: a) Binding mode of compound 9k in the active site of PARP enzyme (PDB ID 1PAX). The native ligand is shown as green ball-and-stick model and compound 9k is shown in cyan ball-and-stick model with $\mathrm{H}$-bonds (black dotted line) with the enzyme residues. b) 2D depiction of the binding mode of compound 9k with $\mathrm{H}$-bonds and pi-pi stacking interactions of the ligand with the macromolecule.

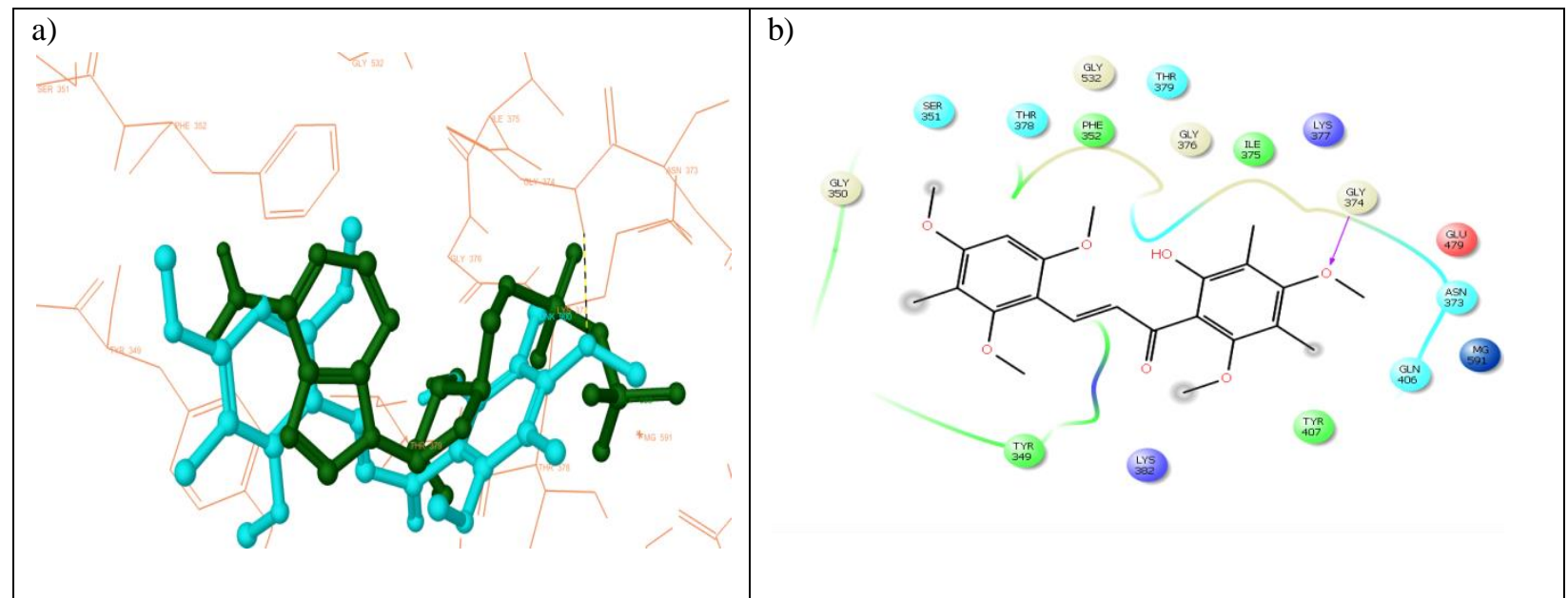

Fig. 4: a) Binding mode of compound 9k in the active site of RNase-L inhibitor (PDB ID: 1YQT). The native ligand is shown as green ball-and-stick model and compound 9k is shown in cyan ball-and-stick model with H-bonds (black dotted line) with the enzyme residues. b) 2D depiction of the binding mode of compound 9k with H-bonds and pi-pi stacking interactions of the ligand with the macromolecule.

Similarly, from Tables 2 and 3the ligand 9gshowed highest docking score of -8.600 with a binding energy of $-73.03 \mathrm{kcal} / \mathrm{mol}$ on 4OQA molecular target compared to all other ligands which indicates the more ligandmolecular target interaction leading for possible use as cancer therapeutics (Table 4) for ligand 9g. Further, Figure 5a shows the binding mode of compound 9gin the active site of PARP-1 enzyme (PDB ID 4OQA). The native ligand is shown as green ball-and-stick model and compound9g is shown in cyan ball-and-stick model with $\mathrm{H}-$-bonds as black dotted line with the enzyme residues. Fig. 5b showsthe 2D depiction of the binding mode of compound $\mathbf{9 g}$ with H-bonds and pi-pi stacking interactions of the ligand with the macromolecule. Moreover, the ligand $9 \mathrm{~g}$ was also found to be active against molecular target $2 \mathrm{ZBH}$, which is representative for Neurodegenerative and psychiatric disorders therapeutic use. The docking score was found to be -4.871 and the binding energy was found to be $-54.26 \mathrm{kcal} / \mathrm{mol}$. The images of the binding modes of the ligands in the active site were provided in Figures 6a\&6b. 


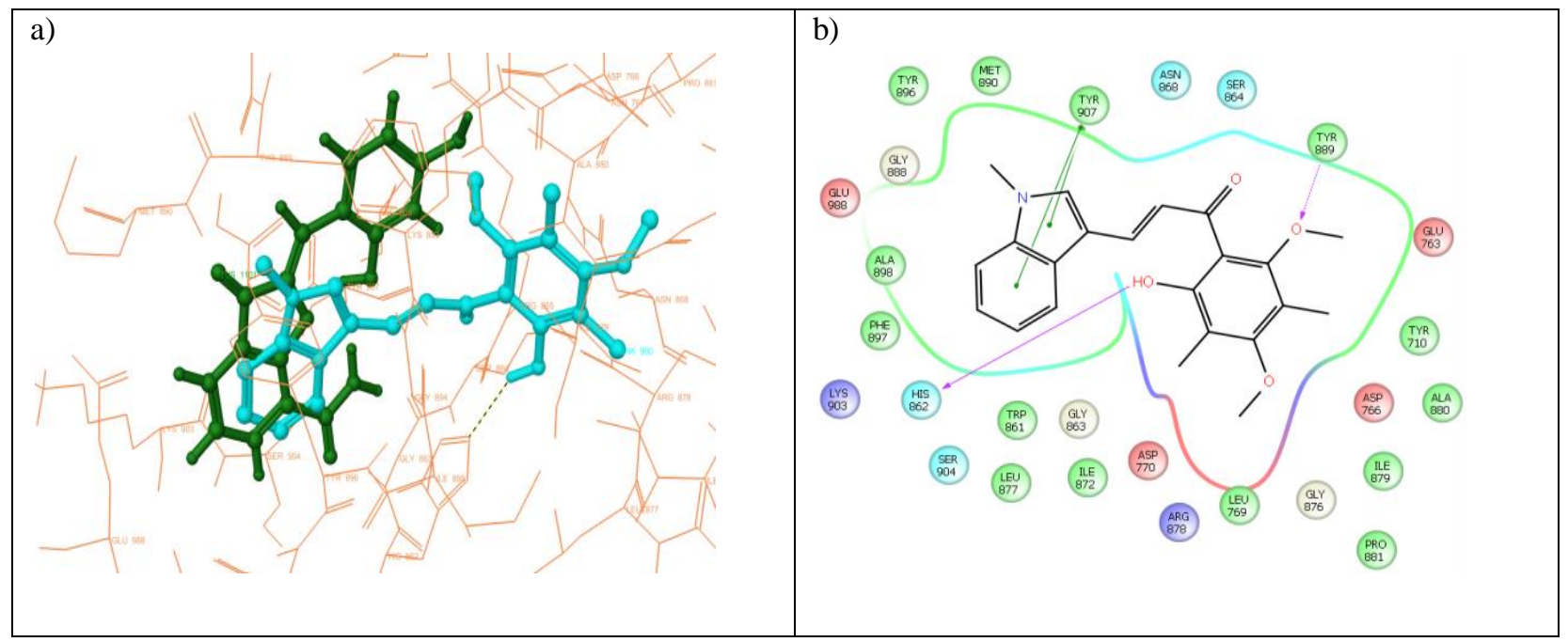

Fig. 5: a) Binding mode of compound 9g in the active site of PARP-1 enzyme (PDB ID 4OQA). The native ligand is shown as green ball-and-stick model and compound $\mathbf{9 g}$ is shown in cyan ball-and-stick model with H-bonds (black dotted line) with the enzyme residues. b) 2D depiction of the binding mode of compound $\mathbf{9 g}$ with H-bonds and pi-pi stacking interactions of the ligand with the macromolecule

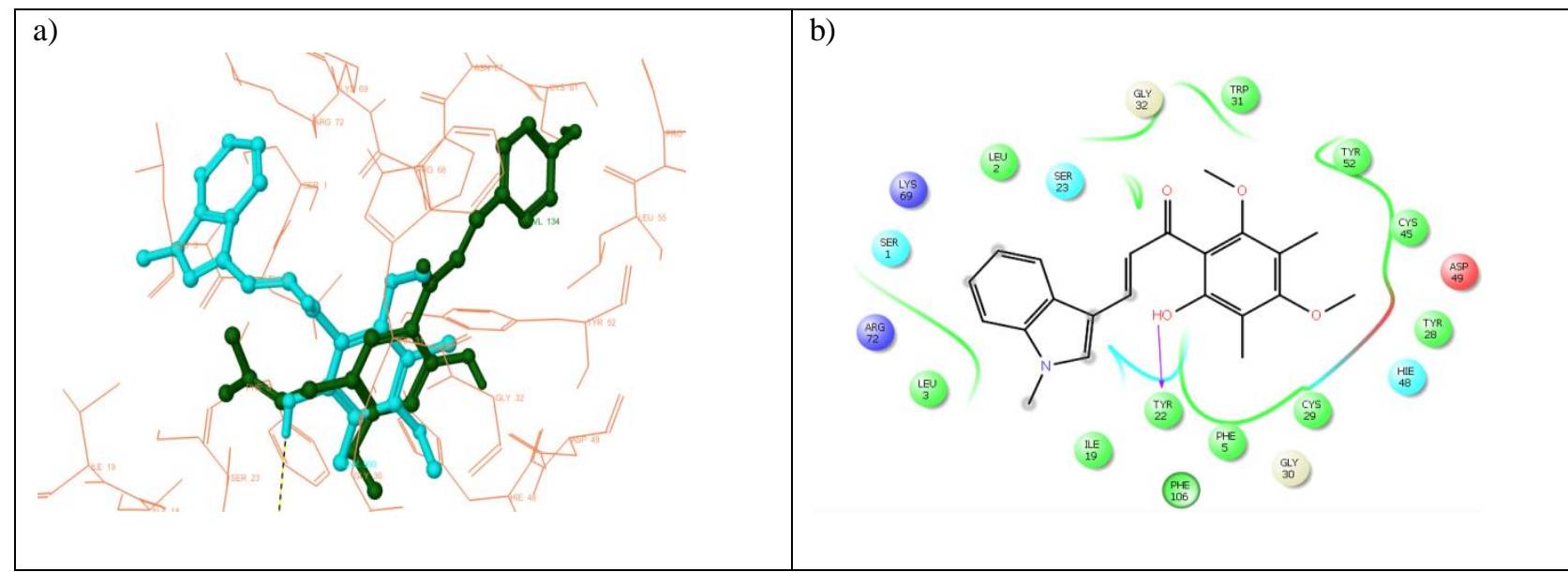

Fig. 6: a) Binding mode of compound $9 \mathrm{~g}$ in the active site of PLA2 enzyme (PDB ID: 2ZBH). The native ligand is shown as green ball-and-stick model and compound $\mathbf{9 g}$ is shown in cyan ball-and-stick model with H-bonds (black dotted line) with the enzyme residues. b) 2D depiction of the binding mode of compound $\mathbf{9 g}$ with $\mathrm{H}$-bonds and pi-pi stacking interactions of the ligand with the macromolecule.

The ligands $9 \mathrm{~m}, \mathbf{9 b}$ and $9 \mathrm{~h}$ were also found to be potentially good for cancer therapeutic use basing on the high docking scores on respective enzyme targets, further the ligand 9b was also useful as viral infections, inflammation, immunosuppression, and parasitic infestations and ligand $\mathbf{9 h}$ is useful as acute promyelocytic leukemia along with breast cancer therapeutic use (Table2, Table 3 and Table 4). The docking score ofthe ligand 9m was -9.004 with a binding energy of $-90.85 \mathrm{kcal} / \mathrm{mol}$ on $3 \mathrm{WIL}$ molecular target for ligand $9 \mathrm{~m}$. Similarly, the docking score of the ligand $\mathbf{9 b}$ was -9.574 with a binding energy of $-78.16 \mathrm{kcal} / \mathrm{mol}$ on $1 \mathrm{ME} 7$ molecular target for ligand 9b. Further, Fig.7a shows the binding mode of compound 9min the active site of CK2 enzyme (PDB ID: 3 WIL). The native ligand is shown as green ball-and-stick model and compound $\mathbf{9 m}$ is shown in cyan ball-and-stick model with H-bonds as a black dotted line with the enzyme residues and Fig.7bshows the 2D depiction of the binding mode of compound $\mathbf{9 m}$ with H-bonds and pi-pi stacking interactions of the ligand with the macromolecule. 


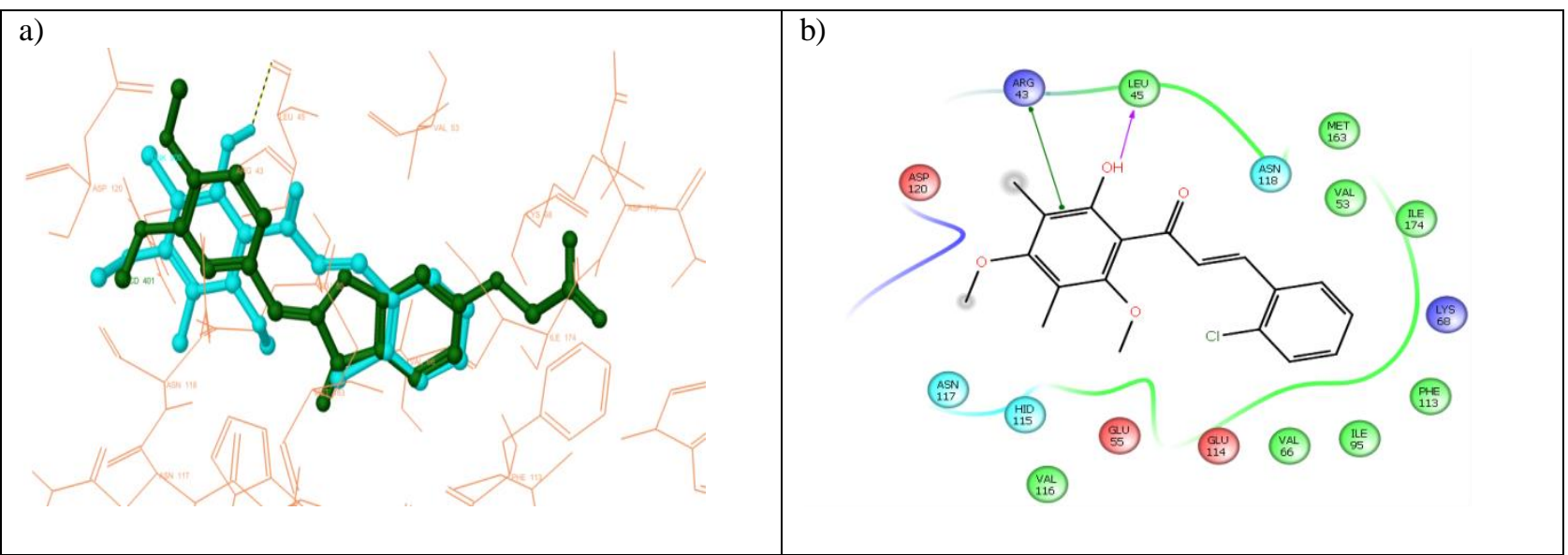

Fig. 7: a) Binding mode of compound $\mathbf{9 m}$ in the active site of CK2 enzyme (PDB ID: 3WIL). The native ligand is shown as green ball-and-stick model and compound $\mathbf{9 m}$ is shown in cyan ball-and-stick model with H-bonds (black dotted line) with the enzyme residues. b) 2D depiction of the binding mode of compound 9m with $\mathrm{H}$-bonds and pi-pi stacking interactions of the ligand with the macromolecule

Further, Fig.8a shows the binding mode of compound 9bin the active site of IMPDH enzyme (PDB ID 1ME7). The native ligand is shown as green ball-and-stick model and compound $\mathbf{9 b}$ is shown in cyan ball-and-stick model with H-bonds (black dotted line) with the enzyme residues. The Figure 8b shows the 2D depiction of the binding mode of compound $\mathbf{9 b}$ with pi-pi stacking interactions of the ligand with the macromolecule.

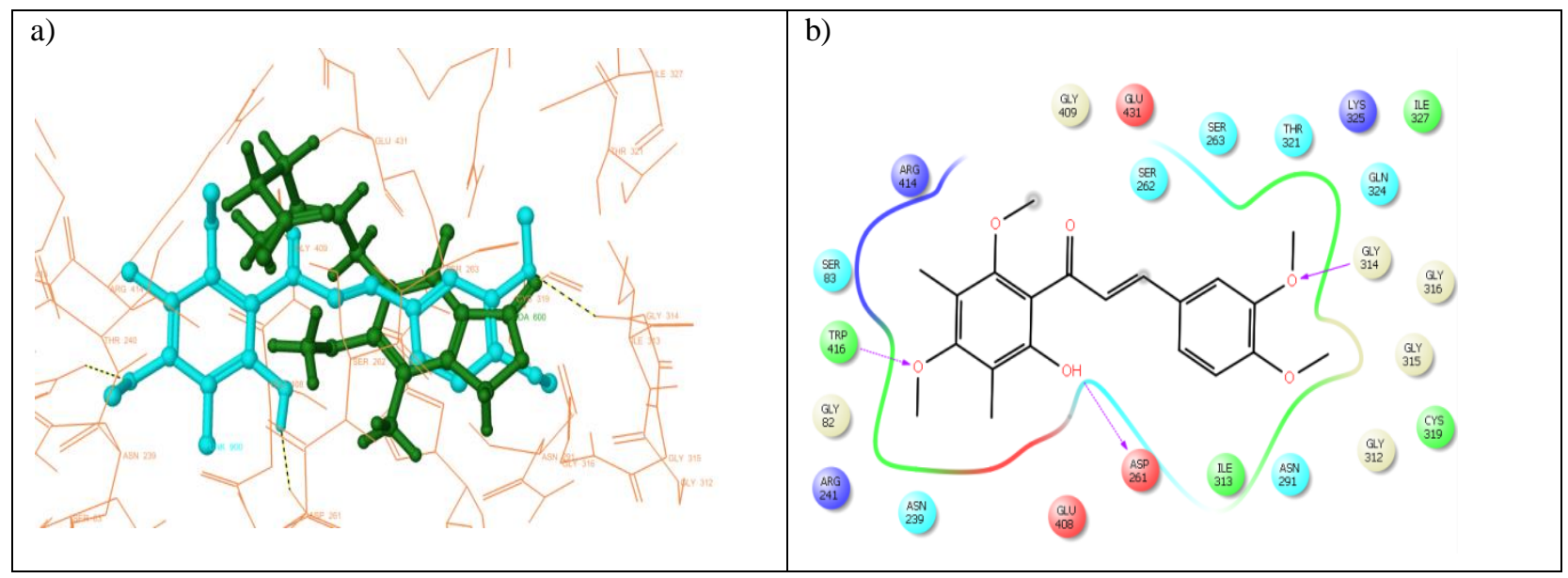

Fig. 8: a) Binding mode of compound 9b in the active site of IMPDH enzyme (PDB ID 1ME7). The native ligand is shown as green ball-and-stick model and compound $\mathbf{9 b}$ is shown in cyan ball-and-stick model with $\mathrm{H}$-bonds (black dotted line) with the enzyme residues. b) 2D depiction of the binding mode of compound 9b with pi-pi stacking interactions of the ligand with the macromolecule.

The Fig. 9a shows the binding mode of compound $\mathbf{9 h}$ in the active site of hRAR enzyme (PDB ID: 1FCZ). The native ligand is shown as green ball-and-stick model and compound $\mathbf{9 h}$ is shown in cyan ball-and-stick model with H-bonds (black dotted line) with the enzyme residues. Fig. 9b shows the 2D depiction of the binding mode of compound $9 \mathrm{~h}$ with pi-pi stacking interactions of the ligand with the macromolecule. 


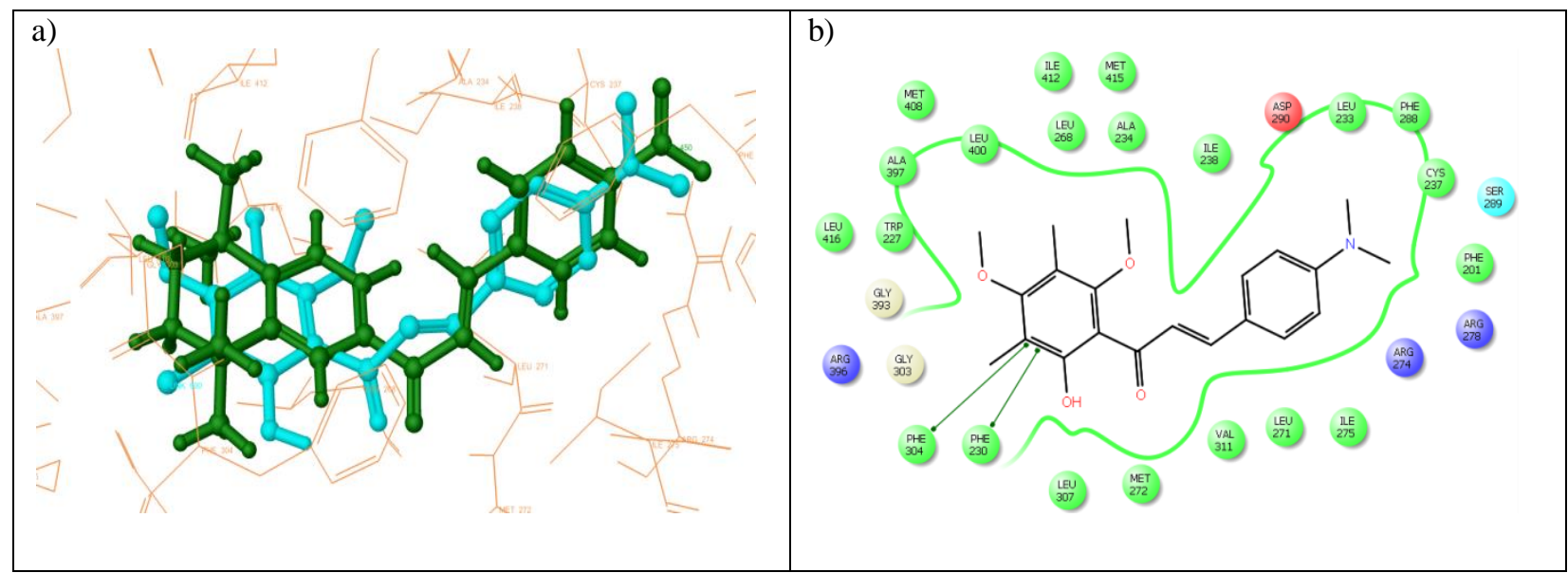

Fig. 9: a) Binding mode of compound 9h in the active site of hRAR enzyme (PDB ID: 1FCZ). The native ligand is shown as green ball-and-stick model and compound $\mathbf{9 h}$ is shown in cyan ball-and-stick model with $\mathrm{H}$-bonds (black dotted line) with the enzyme residues. b) 2D depiction of the binding mode of compound $\mathbf{9 h}$ with pi-pi stacking interactions of the ligand with the macromolecule.

The ligand $\mathbf{9 j}$ was found to be potentially good for immunotherapy therapeutic use basing on the high docking scores on respective enzyme targets (enzyme Streptavidin) (Table 2 and Table 4). The docking score of the ligand 9j was -8.667 on 1SRE (PDBID) molecular target for ligand $\mathbf{9 j}$. Further, Figure 10a shows the binding mode of compound $9 \mathbf{j}$ in the active site of streptavidin (PDB ID: 1SRE). The native ligand is shown as green ball-andstick model and compound $\mathbf{9 j}$ is shown in cyan ball-and-stick model with $\mathrm{H}$-bonds as black dotted line with the enzyme residues.Figure10b $2 \mathrm{D}$ depiction of the binding mode of compound $\mathbf{9 j}$ with pi-pi stacking interactions of the ligand with the macromolecule.

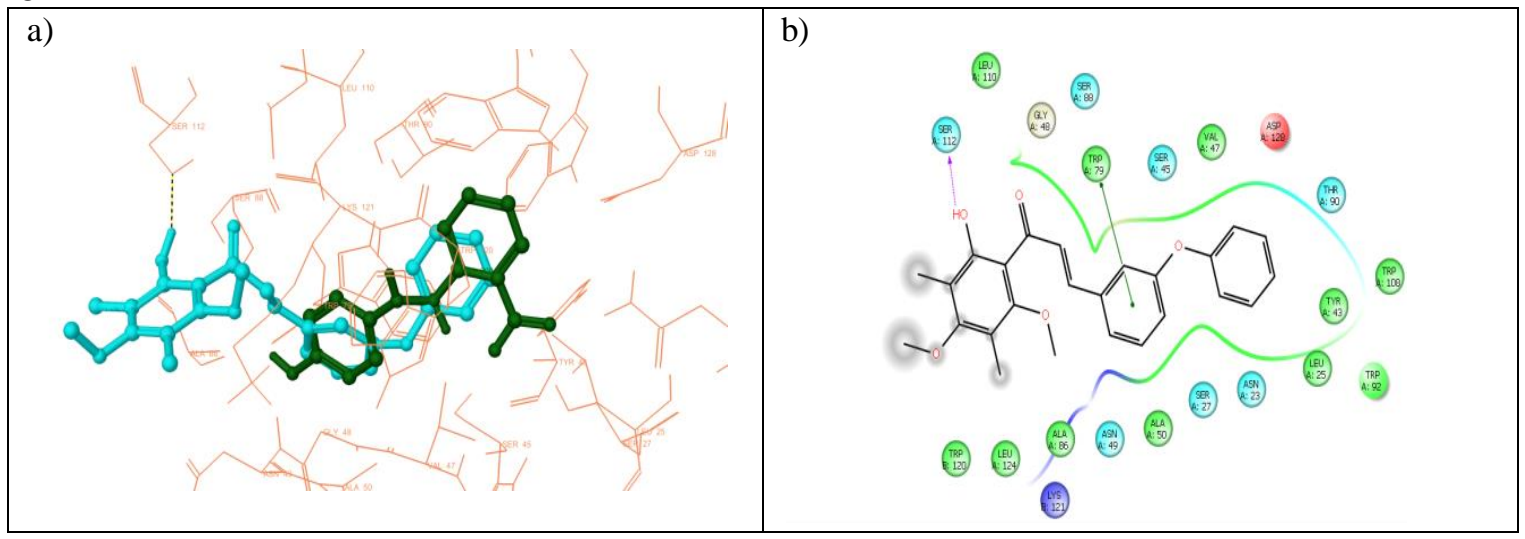

Fig. 10: a) Binding mode of compound 9j in the active site of streptavidin (PDB ID1SRE). The native ligand is shown as green ball-and-stick model and compound $\mathbf{9 j}$ is shown in cyan ball-and-stick model with H-bonds (black dotted line) with the enzyme residues. b) 2D depiction of the binding mode of compound $\mathbf{9 j}$ with pi-pi stacking interactions of the ligand with the macromolecule

\section{Conclusion}

A detailed in silico study was carried out on 17 new $C$-dimethyl chalcones to analyze their therapeutic use. The compounds 9k, 9g, 9m, 9h and $9 \mathrm{~b}$ showed highest XP docking scores with their respective molecular targets under the cancer therapeutic area. Further, the chalcones $9 \mathrm{~g}, 9 \mathbf{k}$ and $9 \mathbf{j}$ were also found to be showed the highest XP docking scores with the respective enzyme targets with neurodegenerative\& psychiatric disorder, HIV and Immunotherapy therapeutic areas.

\section{Acknowledgments}


The authors are thankful to Acharya Nagarjuna University, Guntur, Andhra Pradesh, India and UGC, New Delhi (UGC-MRP/F. No. 39-752/2010 (SR) dated 13-01-2011) for their financial support.

\section{References:}

1. Yao LH, Jiang YM, Shi J. Flavonoids in food and their health benefits. Plant Foods for Human Nutrition, 2004,59: 113-122.

2. Likhitwitayawuid K, Phadungcharoen T, Krungkrai J. Antimalarial xanthones from Garcinia cowa. Planta Medica, 1998, 64: 70-72

3. Haraguchi H, Ishikawa H, Mizutani K, Tamura Y, Kinoshita T. Antioxidative and superoxide scavenging activities of retrochalcones in Glycyrrhiza inflate. Bioorganic and Medicinal Chemistry, 1998, 6: 339-347.

4. Satomi Y. Inhibitory effects of 3'-methyl-3-hydroxy-chalcone on proliferation of human malignant tumor cells and on skin carcinogenesis. International Journal of Cancer, 1993, 55: 506-514.

5. Ryu YB, Curtis-Long MJ, Lee JW. Structural characteristics of flavanones and flavones from Cudraniatricuspidatafor neuraminidase inhibition. Bioorganic and Medicinal Letters, 2009,19: 4912-4915.

6. Anto RJ, Sukumaran K, Kuttan G, Rao MNA, Subbaraju V, Kuttan R. Anticancer and antioxidant activity of synthetic chalcones and related compounds. Cancer Letters, 1995,97: 33-37.

7. Ballesteros JF, Sanz MJ, Ubeda A. Synthesis and pharmacological evaluation of 2'-hydroxychalcones and flavones as inhibitors of inflammatory mediators generation. Journal of Medicinal Chemistry, 1995,38: 2794-2797.

8. Bandgar BP, Gawande SS. Synthesis and biological screening of a combinatorial library of $\beta$-chlorovinyl chalcones as anticancer, anti-inflammatory and antimicrobialagents. Bioorganic and Medicinal Chemistry, 2010,18: 2060-2065.

9. Wu MC, Peng CF, Chen IS, Tsai IL. Antitubercular chromones and flavonoids from Pisonia aculeate.Journal of Natural Products, 2011,74: 976-982.

10. Vasubabu A, Rambabu A, Rao RSC, Giriprasad PV,Haribabu B. Synthesis of ( \pm )-Pisanivanone and other analogs as antitubercolosis agents.Journal of Chemistry, 2013, 5: 1-9.

11. Vasubabu A, Ramesh N, Trimurtulu G, Haribabu B. Synthesis of C-Methyl chalcones as HIVIntegraseinhibitors-Computational approach. Journal of Medicinal Chemistry Research, 2014,23: 877-881.

12. $\mathrm{Yu} \mathrm{YH}$, Liao $\mathrm{CC}, \mathrm{Hsu} \mathrm{WH}$. Increased lung cancer risk among patients with pulmonary tuberculosis: a population cohort study. J Thorac Oncol,2011, 6: 32-37.

13. Wu CY, Hu HY, Pu CY. Aerodigestive tract, lung and haematological cancers are risk factors for tuberculosis: an 8-year population-based study. Int J Tuberc Lung Dis, 2011,15: 125-130.

14. Karnak D, Kayacan O, Beder S. (2002) Reactivation of pulmonary tuberculosis in malignancy. Tumori, 2002, 88: 251-254.

15. Bugata BK, Dowluru SVGK, Avupati VR, Gavalapu VR, Nori, Barla DLS. Synthesis, characterization and in vitro biological evaluation of some new diarylsulfonylurea-chalcone hybrids as potential 5-lipoxygenase inhibitors. Eur. J. Chem, 2013,4: 396-401.

16. Reddy PN, Aparoy TP, Reddy CM, Achari PC, Sridhar R, Reddanna P. Design, synthesis, and biological evaluation of prenylated chalcones as 5-LOX inhibitors. Bioorg. Med. Chem, 2010, 18: 5807-5815.

17. Aparoy P, Reddy KK, Reddanna P.Structure and Ligand Based Drug Design Strategies in the Development of Novel 5- LOX Inhibitors. Curr. Med. Chem, 2012, 19: 3763-3778.

18. Herencia F, Ferrándiz ML, Ubeda A, Domínguez JN, Charris JE, Lobo GM, Alcaraz MJ.Synthesis and anti-inflammatory activity of chalcone derivatives. Bioorg. Med. Chem. Lett, 1998,8: 1169-1174.

19. Detsi A, Majdalani CA, Kontogiorgis M, Litina DH, Kefalas P. Natural and synthetic2'-hydroxy-chalcones and aurones: Synthesis, characterization and evaluation of the antioxidant and soybean lipoxygenase inhibitory activity. Bioorg. Med. Chem, 2009,17: 8073-8085.

20. Babu MA,Shakya N, Prathipati P, Kaskhedikar SG, Saxena AK.Development of 3D-QSAR models for 5Lipoxygenase antagonists: chalcones. Bioorg.Med. Chem, 2002,10: 4035-4041.

21. Wang D, Dubois RN.Eicosanoids and cancer. Nat. Rev. Cancer, 2010,10: 181-193. 
22. Bukhari SN, Lauro G, Jantan I, Bifulco G, Amjad MW.Pharmacological evaluation and docking studies of $\alpha, \beta$-unsaturated carbonyl based synthetic compounds as inhibitors of secretory phospholipase $A_{2}$, cyclooxygenases, lipoxygenase and proinflammatory cytokines. Bioorg. Med.Chem, 2014,22: 4151-4161.

23. Rambabu A, Kumari KJ, Ramana MB, Ramani MV, Subbaraju GV, Babu BH.An improved synthesis of Apigenin and Luteolin.Asian J. Chem, 2016,28: 1139-1143.

24. Reddanna P, Whelan J, Maddipati KR, Reddy CC. Purification of arachidonate 5-lipoxygenase from potato tubers. Methods Enzymol, 1990,187: 268-277.

25. Katsori AM, Dimas CK, Kontogiorgis C, Patsilinakos A, Trangas T, Litina DH.Eur. J. Med. Chem, 2011,46: 2722-2735.

26. Kumari KJ, Singh JS, Durga TV, Rani GU, Babu AV, Narayana KJ, Venkatesan J, Jawed AM, Haribabu B.ChemistrySelect, 2017,

27. Schrödinger, Schrödinger Small-Molecule Drug Discovery Suite Release 2013-1, LLC, New York, NY, 2013.

28. Friesner RA, Murphy RB, Repasky MP, Frye LL, Greenwood JR, Halgren TA, Sanschagrin PC, Mainz DT. Extra Precision Glide: Docking and Scoring Incorporating a Model of Hydrophobic Enclosure for Protein-Ligand Complexes.J. Med. Chem, 2006, 49: 6177-6196.

29. Halgren TA, Murphy RB, Friesner RA, Beard HS, Frye LL, Pollard WT, Banks JL.Glide: A New Approach for Rapid, Accurate Docking and Scoring. 2. Enrichment Factors in Database Screening. J. Med. Chem, 2004, 47: 1750-1759.

30. Friesner RA, Banks JL, Murphy RB, Halgren TA, Klicic JJ, Mainz DT, Repasky MP, Knoll EH, Shaw DE, Shelley M, Perry JK, Francis P,Shenkin PS.Glide: A New Approach for Rapid, Accurate Docking and Scoring. 1. Method and Assessment of Docking Accuracy. J. Med. Chem, 2004, 47: 1739-1749.

31. Liu X, Ouyang S, Yu B, Huang K, Liu Y, Gong J, Zheng S, Li Z, Li H, Jiang H.PharmMapper Server: a web server for potential drug target identification via pharmacophore mapping approach. Nucl. Acids Res,2010,38: W609-W614.

32. Berman HM, Westbrook J, Feng Z, Gilliland G, Bhat TN, Weissig H, Shindyalov IN, Bourne PE.The Protein Data Bank. Nucl. Acids Res, 2000,28: 235-242.

33. Ruf A,Murcia JMD, Murcia GD, Schulz GE.Structure of the catalytic fragment of poly(AD-ribose) polymerase from chicken. Proc. Natl. Acad. Sci USA, 1996,93: 7481-7485.

34. Patel MR, Bhatt A, Steffen JD, Chergui A, Murai J, Pommier Y, Pascal JM, Trombetta LD, Fronczek FR.Discovery and structure-activity relationship of novel 2,3-dihydrobenzofuran-7-carboxamide and 2,3dihydrobenzo-furan-3(2H)-one-7-carboxamide derivatives as poly (ADP-ribose) polymerase-1 inhibitors. $J$. Med. Chem, 2014,57: 5579-5601.

35. Nakanishi I, Murata K, Nagata N, Kurono M, Kinoshita T, Yasue M, Miyazaki T, Hirasawa A, Tsujimoto G, Kitaura K, Identification of protein kinase CK2 inhibitors using solvent dipole ordering virtual screening PDB ID: 3WIL (To be published). https://www.rcsb.org/structure/3WIL.

36. Klaholz BP, Mitschler A, Moras D.Structural basis for isotype selectivity of the human retinoic acid nuclear receptor. J. Mol. Biol, 2000,302: 155-170.

37. Kumar S, Damodar NC, Jain R, Singh N, Sharma S, Kaur P, Haridas M, Srinivasan A,Singh TP, PDB ID: 2ZBH. Crystal structure of the complex of phospholipase A2 with Bavachalcone from Aervalanata at 2.6 A resolution.

38. Karcher A, Buttner K, Martens B, Jansen RP, Hopfner KP.X-Ray structure of RLI, an essential twin cassette ABC ATP ase involved in ribosome biogenesis and HIV capsid assembly. Structure, 2005,13: 649659.

39. Weber PC, Pantoliano MW, Simons DM,Salemme FR.Structure based design of synthetic azobenzene ligands for streptavidin. J. Am. Chem Soc, 1994,116: 2717-2724.

40. Prosise GL, Wu J, Luecke H.J. Crystal structure of tritrichomanasfoetus inosine monophosphate dehydrogenade in complex with the inhibitor ribavirin monophosphate reveals a catalysis-dependent ionbinding site. Biol. Chem, 2002, 277: 50654-50659. 